\title{
Systemic or topical application of plasminogen activator inhibitor with extended half-life (VLHL PAI-1) reduces bleeding time and total blood loss
}

\author{
JERZY JANKUN $^{1,2}$, RICK KECK ${ }^{1}$, STEVEN H. SELMAN ${ }^{1}$ and EWA SKRZYPCZAK-JANKUN ${ }^{1}$ \\ ${ }^{1}$ Urology Research Center, Department of Urology, The University of Toledo-Health Science Campus, \\ 3000 Arlington Ave., Toledo, OH 43614, USA; ${ }^{2}$ Department of Clinical Nutrition, \\ Medical University of Gdansk, Debinki 7, 80-211 Gdansk, Poland
}

Received April 12, 2010; Accepted May 26, 2010

DOI: 10.3892/ijmm_00000491

\begin{abstract}
Civilian and military trauma patients consist of a disproportional number of young people, causing a considerable burden to society in terms of disability and premature death. Hemorrhage is a leading cause of mortality in this group of patients and the novel methods to reduce bleeding would be welcomed. Management of bleeding following major trauma includes hemostatic agents that offer effective clotting. However a very limited number of agents control secondary bleeding triggered by lysis of the clot. Fibrinolysis depends on the balance between tissue plasminogen activator (tPA), activating plasminogen to plasmin initiating fibrinolysis, and plasminogen activator inhibitor type 1 (PAI-1) inhibiting tPA and preventing lysis. The drugs available on the market that prevent the activation of plasminogen have been used successfully, but have some side effects and limited efficacy for the control of localized bleeding in the surgical setting. Inhibitors of tPA, initiator of clot fibrinolysis, have not yet found their way into the clinical arena. Plasminogen activator inhibitor-1, the major specific inhibitor of tPA, can be used to limit fibrinolysis. Unfortunately, PAI-1 has a short halflife of $\sim 2 \mathrm{~h}$ and is rapidly converted to the latent form. A recombinant PAI-1 with very long half-life developed in our laboratory (a two-point mutant, VLHL PAI-1, half-life over $700 \mathrm{~h}$ ) has clinical potential as an agent to promote hemostasis in several scenarios including surgical injury, trauma, and PAI-1 deficiency. Here we report testing of VLHL PAI-1 as a potent inactivator of fibrinolysis reducing total blood loss while applied systemically or topically in experimental animals. The very long half-life of VLHL PAI-1 may provide an advantage in the important physiological mechanism to protect clots from premature dissolution, when applied
\end{abstract}

Correspondence to: Professor Jerzy Jankun, Urology Research Center, Department of Urology, The University of Toledo-Health Science Campus, 3000 Arlington Ave., Toledo, OH 43614, USA E-mail: jerzy.jankun@utoledo.edu

Key words: PAI-1, blood clotting, bleeding time, blood loss topically or systemically to prevent excessive bleeding in the surgical and trauma setting and possibly in PAI-1 deficient patients.

\section{Introduction}

The recovery of hemorrhagic trauma patients has improved over recent years but there is still a need to control bleeding in order to reduce morbidity and mortality $(1,2)$. It has been reported that regardless of advances in trauma care, uncontrolled bleeding contributes up to $40 \%$ of trauma patient's deaths (3). Civilian and military trauma cases affect a disproportional number of young people, thus the burden to society in terms of disability and premature death, is considerable.

Management of bleeding following major trauma includes hemostatic agents that offer effective clotting but a very limited number of agents are available to control secondary bleeding set off by fibrinolysis. Fibrinolysis depends on the balance between tissue plasminogen activator (tPA), activating plasminogen to plasmin causing fibrinolysis, and plasminogen activator inhibitor type 1 (PAI-1) inhibiting tPA and thus preventing fibrinolysis. There are drugs on the market that prevent the activation of plasminogen through direct interaction with the lysine binding site of plasminogen. The inhibition of plasmin activity has been explored by using 6amino caproic acid ( $\varepsilon$-amino caproic acid, Amicar ${ }^{\circledR}$, Lederle) or tranexamic acid. However, while these drugs have been used successfully, they have some side effects. In addition they have limited efficacy for the control of localized bleeding in the surgical setting (4).

Inhibitors of tPA, initiator of clot fibrinolysis, have not yet found their way into the clinical arena. The plasminogen activator inhibitor- 1 is the major specific inhibitor of tPA and can be used to limit fibrinolysis. The major clinical obstacle is its short half-life of $\sim 2 \mathrm{~h}$ of PAI-1. The wild-type PAI-1 converts from active to latent form. A form of PAI-1 with very long half-life, which has been developed in our laboratory (a two-point mutant, VLHL PAI-1, half-life over $700 \mathrm{~h}$ ) has clinical potential as an agent to promote hemostasis in several scenarios including surgical injury, trauma, and PAI-1 deficiency, as well as in rebleeding following initial hemostasis. In our previous publications we have reported that VLHL PAI-1 


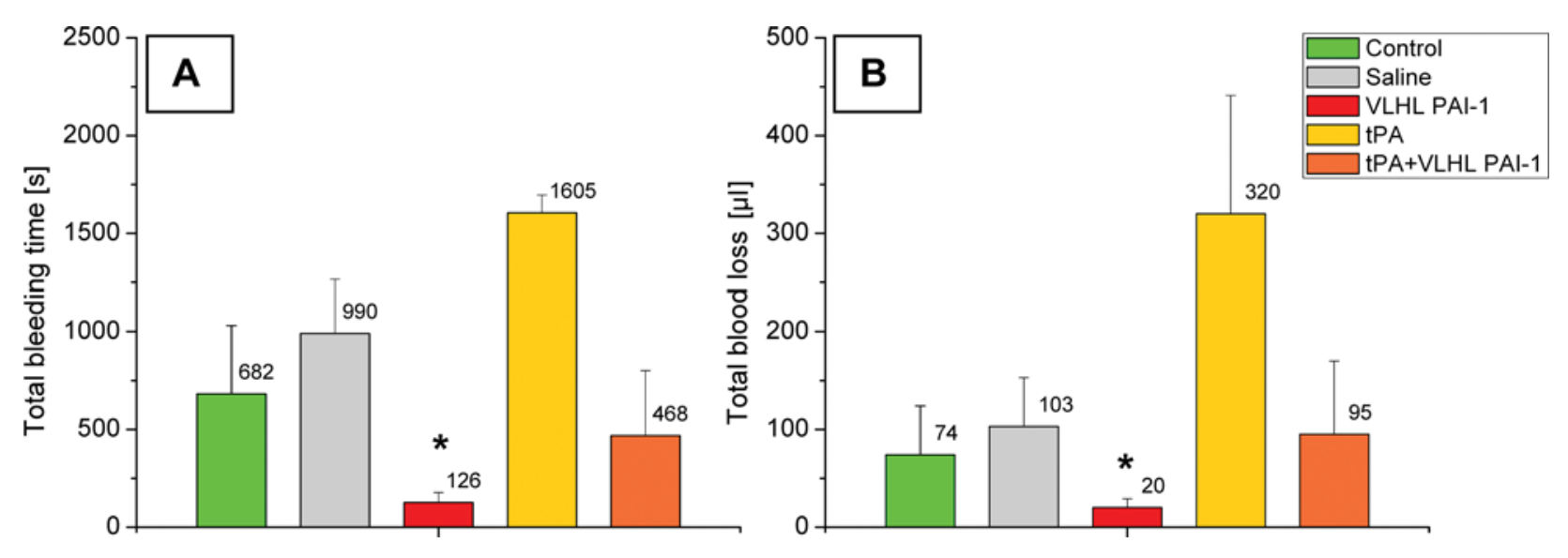

Figure 1. Total time of bleeding (A) and total blood loss (B) in control animals and animals infused with VLHL PAI-1 and VLHL PAI-1+tPA. $n=4$, asterisk indicates statistical significance at a $\mathrm{P}<0.05$ between VLHL PAI-1 group and controls.

is an effective inactivator of fibrinolysis ex vivo and in vivo in an animal model while administered systemically (5-7). The current study provides evidence that VLHL PAI-1 is equally potent as an inactivator of fibrinolysis and total blood loss when applied either systemically or topically in experimental animals.

\section{Materials and methods}

Proteins. The mutation of two amino acids (Gln197 $\rightarrow$ Cys, Gly355 $\rightarrow$ Cys) in human wPAI-1 [SwissPROT P05121 (8)] produces VLHL PAI-1 with half-life of over $700 \mathrm{~h}(9)$. Composition of this protein and purification were described previously by our group $(5,10)$. Fully active human tPA, product number HTPA-TC was purchased from Molecular Innovations, Novi, MI.

Animals. Mice used were retired male breeders, C57BL/6J, Jackson Labs, Bar Harbor, Maine, fed ad libitum. All animal experiments were performed according to the institutional ethics guidelines.

Systemic administration. Animals were anesthetized via gas inhalation (1.0-2.0\% isoflurane). The left jugular vein was surgically exposed and canulated with a PE 10 catheter to administer saline, tPA and PAI-1. Flow rate was controlled with a syringe pump (Medex, Inc., Duluth, GA). All animals received the same volume of fluids. The pump rate used was $0.3 \mathrm{ml} / \mathrm{h}$ for a total volume of $300 \mu \mathrm{l}$. The tail was immersed in warm $\left(37^{\circ} \mathrm{C}\right)$ saline during the infusion time. Immediately after the infusion, $5 \mathrm{~mm}$ of the tip of the tail was cut off using a fresh scalpel blade and placed in a vial of warmed $\left(37^{\circ} \mathrm{C}\right)$ saline $(50 \mathrm{ml})$. Bleeding episodes were monitored and recorded for $30 \mathrm{~min}$. Animals were euthanized at the end of the bleeding observation period. Animals were divided into 5 groups $(n=4)$.

Animals in group I served as a control group that received no surgery or systemic infusion, but had their tails warmed for $1 \mathrm{~h}$ prior to clipping. Animals in group II received surgery and saline infusion for $1 \mathrm{~h}$ prior to clipping their tails. Animals in group III were infused with saline for $30 \mathrm{~min}$ followed by VLHL PAI-1 (total dose $225 \mu \mathrm{g}$ ) for $30 \mathrm{~min}$. Animals in group IV were infused with tPA (total dose $108 \mu \mathrm{g}$ ) for $30 \mathrm{~min}$ followed by saline for $30 \mathrm{~min}$ prior to clipping the tail. Animals in group $\mathrm{V}$ were infused with tPA (total dose $108 \mu \mathrm{g}$ ) for 30 min followed by VLHL PAI-1 (total dose $225 \mu \mathrm{g}$ ) for 30 min prior to clipping the tail.

External application. Animals were anesthetized via gas inhalation (1.0-2.0\% isoflurane). Five millimetres of the tip of the tail was cut off using a fresh scalpel blade and placed into a $1.5 \mathrm{ml}$ vial containing either $1.0 \mathrm{ml}$ of saline or $1.0 \mathrm{ml}$ of VLHL PAI-1. Bleeding episodes were monitored and recorded for $30 \mathrm{~min}$. Animals were euthanized at the end of the bleeding observation period.

Animals were divided into 4 groups of 8 animals each. In group Ia (control) the animal's clipped tails were placed in saline. In group IIa tails were placed in $300 \mu \mathrm{g}$ VLHL PAI- $1 / \mathrm{ml}$, in group IIIa, in $75 \mu \mathrm{g}$ VLHL PAI-1/ml, and in group IVa in $19 \mu \mathrm{g}$ VLHL PAI- $1 / \mathrm{ml}$.

All bleeding episodes were timed and a summary yielded a total bleeding time. Hemoglobin concentration was determined in all collection vials spectrophotometrically and converted to blood loss volume utilizing a standardized curve.

Statistical analysis was carried out using Origin 8 program (OriginLab Corporation, Northampton, MA 01060). Statistical significance was set at a $\mathrm{P}<0.05$ as calculated using ANOVA test.

\section{Results}

Surgery and injection of saline slightly increase bleeding time and blood loss but it was not statistically significant. The positive control group that received infusion of tPA showed an increase time of bleeding and blood loss. Infusion of tPA followed by infusion of VLHL PAI-1 brings bleeding time and blood loss to the control values. However, statistically significant reduction of bleeding time and total blood loss was seen when only VLHL PAI-1 was infused (Fig. 1).

As can be seen in Fig. 2 when animals were treated topically with VLHL PAI-1 differences in total bleeding time between treated and non-treated animals were smaller and 


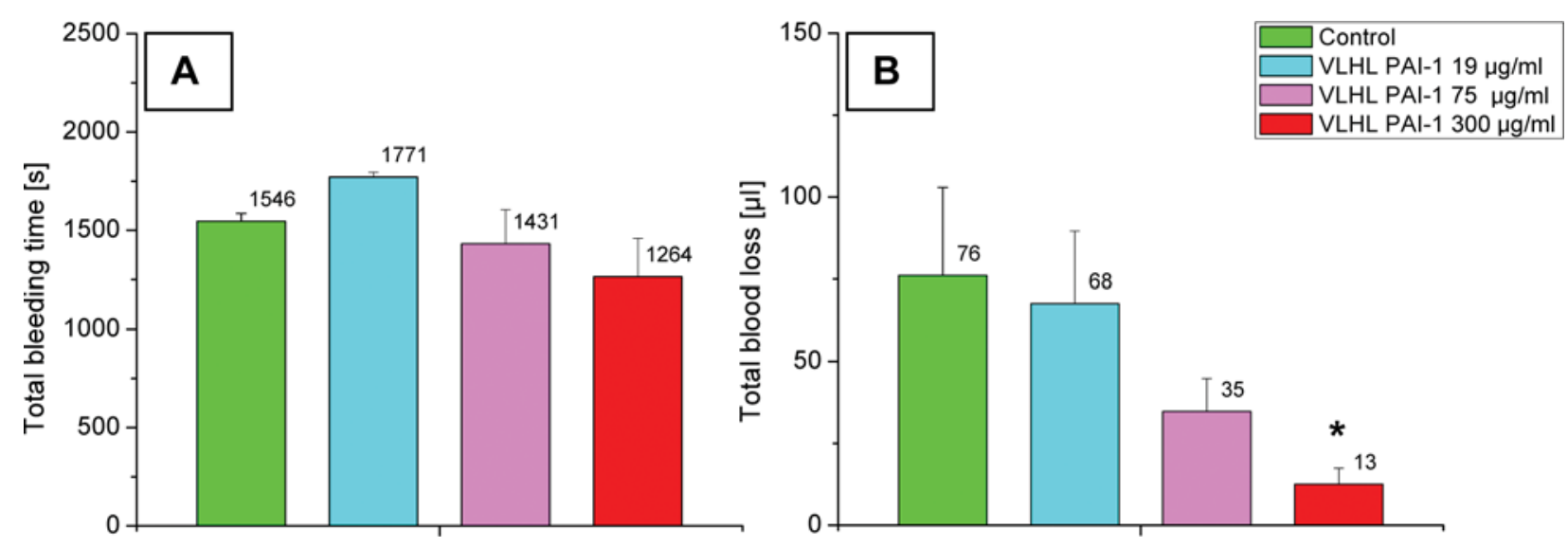

Figure 2. Total time of bleeding (A) and total blood loss (B) in control animals and animals treated topically with VLHL PAI-1 at different concentrations . $\mathrm{n}=8$, asterisk indicates statistical significance at a $\mathrm{P}<0.05$ between VLHL PAI-1 group and control.
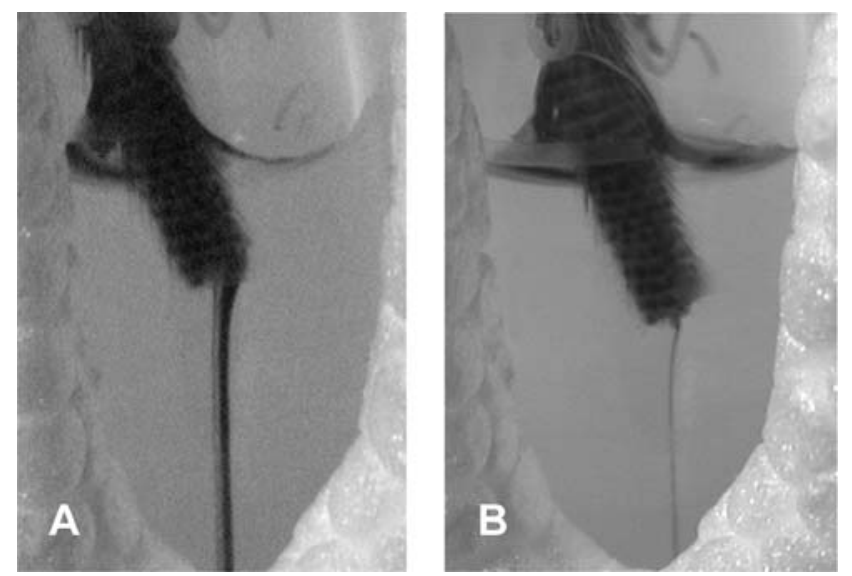

Figure 3. Bleeding from multiple or single blood vessels after amputation of tail tip immersed in saline or saline solution of VLHL PAI-1. Bleeding time was recorded when bleeding intensity was high (A) or low (B). The more reliable measure of reducing bleeding by VLHL PAI-1 is total blood loss.

not significant. We have noticed in this group that animals bled frequently (on/off) but the intensity of bleeding was drastically different as can be seen in Fig. 3. Only the bleeding episodes were recorded and not the intensity of the blood stream. Bleeding from multiple or single vessels were recorded equally. We conclude that at least in these groups total time of bleeding was a weak indicator of blood loss.

Remarkably, as can be seen in Figs. 1 and 2 animals treated topically and systemically with similar dose of VLHL PAI-1 showed practically the same reduction of blood loss. Control groups, whether treated topically or systemically were also the same. Furthermore, when applied topically, reduction of total blood loss was VLHL PAI-1 concentration dependent with $50 \%$ and $80 \%$ blood loss reduction at $75 \mu \mathrm{g} / \mathrm{ml}$ and $300 \mu \mathrm{g} / \mathrm{ml}$ respectively.

\section{Discussion}

Previously we have reported that systemic application of VLHL PAI-1 reduces bleeding time and total blood loss in
C57BL/6J mouse (7). In this study we have used a larger number of animals and added an additional control group. This group included animals in whom no surgery was done and there was no treatment.

VLHL PAI-1 is the specific inhibitor of tPA and acts by forming a 1:1 complex, followed by the formation of a covalent bond between the active site of the protease and the reactive center of the serpin. PAI-1 binds to fibrin but not to fibrinogen and thus can localize itself at the sites of injury (11). Plasminogen activator inhibitor-1 accumulated within thrombi retains its complete tissue-type plasminogen inhibitory activity protecting the clot from premature dissolution (12). All these properties make PAI-1 an attractive anti fibrinolytic agent.

Usage of inhibitors of fibrinolysis to limit bleeding was explored before by others. Reilly et al found that fibrin clot lysis in rats was inhibited in a dose-responsive manner by infusion of active wild-type of PAI-1 (13). In other in vivo studies using a rabbit ear model of blood loss it was found that the active form of wPAI- 1 and $\varepsilon$-amino caproic acid (EACA) reduce the bleeding induced by tPA. However, wPAI-1 reduced hemorrhage more effectively (14). These results support our findings and indicate that PAI-1 inhibits fibrinolysis in vivo. Nevertheless, one of the most critical hurdles in using wPAI-1 as a hemostatic drug is its short halflife $\left(t_{1 / 2}=2 \mathrm{~h}\right)(15,16)$. VLHL PAI-1 with its very long half-life can eliminate this problem.

In conclusion, we wanted to evaluate the effect of VLHL PAI-1 on hemostasis and we have demonstrated that recombinant human VLHL PAI-1 administered topically or systemically is an efficient inhibitor of fibrin clot degradation. It reduces total blood loss and total time of bleeding. However, our results show that in some cases time of bleeding alone may be a weak indicator of blood clot protecting activity of the hemostatic agents. Very long halflife PAI-1 when applied topically or systemically may provide an important physiological mechanism to protect clots from premature dissolution in the surgical and trauma setting and might provide a promising remedy in PAI-1 deficiency. 


\section{Acknowledgements}

We thank Dr R. Hart (President, PharmaIP LLC, Greenwich, CT, USA) for helpful remarks, discussions and support. This study was supported in part by grants from: PharmaIP LLC, and the Frank D. Stranahan Endowment Fund for Oncological Research.

\section{References}

1. Rossaint R, Cerny V, Coats TJ, et al: Key issues in advanced bleeding care in trauma. Shock 26: 322-331, 2006.

2. Rossaint R, Duranteau J, Stahel PF and Spahn DR: Nonsurgical treatment of major bleeding. Anesthesiol Clin 25: 35-48, 2007.

3. Fernandez-Mondejar E, Pino-Sanchez F, Tuero Leon G, Rodriguez Bolanos S and Castan Ribas P: Management of hemorrhage in patients with abdominal trauma: application of the European Guidelines for the management of bleeding following major trauma. Cir Esp 85 (Suppl. 1): S29-S34, 2009.

4. Ghosh K, Shetty S, Jijina F and Mohanty D: Role of epsilon amino caproic acid in the management of haemophilic patients with inhibitors. Haemophilia 10: 58-62, 2004.

5. Jankun J, Aleem AM, Selman SH, et al: Highly stable plasminogen activator inhibitor type one (VLHL PAI-1) protects fibrin clots from tissue plasminogen activator-mediated fibrinolysis. Int J Mol Med 20: 683-687, 2007.

6. Jankun J, Aleem AM, Struniawski R, Lysiak-Szydlowska W, Selman SH and Skrzypczak-Jankun E: Accelerated thrombus lysis in the blood of plasminogen activator inhibitor deficient mice is inhibited by PAI-1 with a very long half-life. Pharmacol Rep 61: 673-680, 2009.

7. Jankun J, Selman SH, Keck RW, Lysiak-Szydlowska W and Skrzypczak-Jankun E: Very long half-life plasminogen activator inhibitor type 1 reduces bleeding in a mouse model. BJU Int 105: 1469-1476, 2010.
8. Pannekoek H, Veerman H, Lambers H, et al: Endothelial plasminogen activator inhibitor (PAI): a new member of the Serpin gene family. EMBO J 5: 2539-2544, 1986.

9. Chorostowska-Wynimko J, Swiercz R, Skrzypczak-Jankun E, Wojtowicz A, Selman SH and Jankun J: A novel form of the plasminogen activator inhibitor created by cysteine mutations extends its half-life: relevance to cancer and angiogenesis. Mol Cancer Ther 2: 19-28, 2003.

10. Jankun J, Aleem AM, Specht Z, et al: PAI-1 induces cell detachment, downregulates nucleophosmin (B23) and fortilin (TCTP) in LnCAP prostate cancer cells. Int J Mol Med 20: 11-20, 2007.

11. Smolarczyk K, Boncela J, Szymanski J, Gils A and Cierniewski CS: Fibrinogen contains cryptic PAI-1 binding sites that are exposed on binding to solid surfaces or limited proteolysis. Arterioscler Thromb Vasc Biol 25: 2679-2684, 2005.

12. Reilly CF and Hutzelmann JE: Plasminogen activator inhibitor1 binds to fibrin and inhibits tissue-type plasminogen activatormediated fibrin dissolution. J Biol Chem 267: 17128-17135, 1992.

13. Reilly CF, Fujita T, Mayer EJ and Siegfried ME: Both circulating and clot-bound plasminogen activator inhibitor-1 inhibit endogenous fibrinolysis in the rat. Arterioscler Thromb 11: 1276-1286, 1991.

14. Racanelli AL, Diemer MJ, Dobies AC, Dubin JR and Reilly TM: Comparison of recombinant plasminogen activator inhibitor-1 and epsilon amino caproic acid in a hemorrhagic rabbit model. Thromb Haemost 67: 692-696, 1992.

15. Swiercz R, Keck RW, Skrzypczak-Jankun E, Selman SH and Jankun J: Recombinant PAI-1 inhibits angiogenesis and reduces size of LNCaP prostate cancer xenografts in SCID mice. Oncol Rep 8: 463-470, 2001.

16. Swiercz R, Skrzypczak-Jankun E, Merrell MM, Selman SH and Jankun J: Angiostatic activity of synthetic inhibitors of urokinase type plasminogen activator. Oncol Rep 6: 523-526, 1999. 